\title{
EMPIRICAL RESEARCH ON THE RELATION BETWEEN INTERNAL INFLUENCING FACTORS ON THE INTERNATIONALIZATION: ALBANIAN SMES
}

\author{
Emi Hoxholli ${ }^{*}$, Donika Kërçini ${ }^{1}$ \\ ${ }^{1 *}$ Faculty of Economics and Agrobusiness, Agricultural University of Tirana, Albania; \\ *Corresponding Author Emi Hoxholli, e-mail: emilihoxholli@yahoo.com; dkercini@ubt.edu.al;
}

Received December 2019; Accepted January 2020; Published February 2020;

DOI: https://doi.org/10.31407/ijees10.126

\begin{abstract}
Small and medium enterprises (SMEs) form an essential source of growth and dynamics for advanced industrialized countries and for emergent economies (Agndal, Chetty 2007; Javalgi, Todd, 2011). According to National Strategy for Business Development and Investments 2014-2020, one of the goals of Albanian government for the midterm period is to constitute a competitive country through stimulation of SMEs and showing them the new opportunities that offer European and global market. During 2018, from the total of 162,835 active enterprises in Albania, 99\% are micro, small and medium enterprises. They contribute in $73 \%$ of the Gross Domestic Product GDP and 71\% of employment. Through this research we aim to identify the relation between the internal factors of SMEs and performance of internationalization for internationally active Albanian SMEs. This objective is based on four hypothesis, which will be tested based on bivariate analysis using Kendall's tau-b correlation coefficient, this is a nonparametric measure of the strength and direction of association that exist between two variables measured on at least ordinal scale. We have four regression models, one for each hypothesis that we will help us understand how the internationalization process can be forecasted based on the variables.
\end{abstract}

Keywords: empirical, internationalization, internal influencing factors, SMEs, models. 